\title{
Virtual Learning Innovations for Continuing Clinical Education during COVID-19
}

\author{
Katarina Hoernke ${ }^{1}$ (D) Hari McGrath ${ }^{2}$ (D) $\cdot$ Jye Quan Teh $^{3}\left(\right.$ D $\cdot$ Oliver Salazar $^{4}$ (D)
}

Accepted: 22 September 2020 / Published online: 30 September 2020

(C) International Association of Medical Science Educators 2020

We read with great interest the article by Goldenberg et al. [1] and would like to offer our perspective on virtual learning experiences as medical students from four UK universities. During the COVID-19 pandemic, our learning was shifted online with clinical teaching largely suspended. We believe that innovative solutions to virtual teaching can facilitate valuable and safe educational experiences. Furthermore, these can support the message that engaging with real patients is integral, not extraneous, to becoming a physician.

During the COVID-19 pandemic, medical students have expressed dissatisfaction due to a lack of clinical teaching and patient interaction [2]. The need for novel ways to engage with patients remotely and safely is evident. As the authors highlighted, online resources can be limited in their ability to help students develop clinical skills and professionalism. We agree that traditional online teaching resources cannot fully substitute in-person learning. However, there are a number of innovative virtual solutions which could provide the opportunity for safe and meaningful interaction with clinical teams and real patients. We would like to outline some here for consideration by the authors.

Katarina Hoernke

k.hoernke@uea.ac.uk

Hari McGrath

hari.mcgrath@kcl.ac.uk

Jye Quan Teh

jqt20@cam.ac.uk

Oliver Salazar

oliver.salazar19@imperial.ac.uk

1 Norwich Medical School, University of East Anglia, Norwich, UK

2 GKT School of Medical Education, King's College London, London, UK

3 University of Cambridge School of Clinical Medicine, Cambridge, UK

4 Faculty of Medicine, Department of Medicine, Imperial College London, London, UK
With many outpatient and inpatient services utilizing digital technologies during the pandemic, we see opportunities for students to get involved. Virtual ward rounds, such as those described by Schwamm et al. [3], may be refined to involve medical students in remote clinical care. Students could tunein to ward rounds and might benefit from having designated times for asking questions relating to the cases presented, as well as following up patients. A more interactive approach could be a virtual ward round specifically for teaching purposes. One of our authors (OS) attended a mixed-reality teaching round where they saw the patient from the clinician's point of view with electronic records superimposed on the Microsoft HoloLens headset image (Microsoft Inc., Redmond, Washington) [4]. Students were able to interact with the clinician remotely, which facilitated participation and clinical reasoning. Student involvement through virtual ward rounds could provide an opportunity for students to reach clerkship learning objectives whilst minimizing the risk of exposure and nosocomial transmission and reducing demand for personal protective equipment.

As leaders in medical education, the authors have a unique opportunity to explore novel ways of delivering medical education using digital technology. Should remote learning become necessary again, technological innovations could facilitate clinical learning and the development of core competencies.

Authors' Contributions $\mathrm{KH}, \mathrm{HM}$ and JQT planned the correspondence letter. OS provided a first-hand account of digital medical education. All authors discussed, wrote and edited the manuscript.

Data Availability Not applicable.

\section{Compliance with Ethical Standards}

Conflict of Interest The authors declare that they have no conflict of interest.

Ethics Approval Not applicable 
Consent to Participate Not applicable.

Consent for Publication Not applicable.

Code Availability Not applicable.

\section{References}

1. Goldenberg MN, Hersh DC, Wilkins KM, Schwartz ML. Suspending medical student clerkships due to COVID-19. Med Sci Educ. 2020:1-4. https://doi.org/10.1007/s40670-020-00994-1.
2. Dedeilia A, Sotiropoulos MG, Hanrahan JG, Janga D, Dedeilias P, Sideris M. Medical and surgical education challenges and innovations in the COVID-19 Era: a systematic review. In Vivo. 2020;34(3 Suppl):1603-11. https://doi.org/10.21873/invivo.11950.

3. Schwamm LH, Estrada J, Erskine A, Licurse A. Virtual care: new models of caring for our patients and workforce. Lancet Digit Health. 2020;2(6):e282-5. https://doi.org/10.1016/S2589-7500(20)30104-7.

4. Gallagher L, Alford J. Mixed-reality headsets in hospitals help protect doctors and reduce need for PPE. In: Imperial News. 2020. https://www.imperial.ac.uk/news/197617/mixed-reality-headsetshospitals-help-protect-doctors/ [Accessed 20th July 2020].

Publisher's Note Springer Nature remains neutral with regard to jurisdictional claims in published maps and institutional affiliations. 